\title{
Zenith total delay study of a mesoscale convective system: GPS observations and fine-scale modeling
}

By L. CUCURULL ${ }^{1 *}$, J. VILÀ ${ }^{2}$ and A. RIUS ${ }^{1},{ }^{1}$ Institut of Space Studies of Catalonia (IEEC/CSIC), Edif. Nexus-204, c/ Gran Capità 2-4, E-08034 Barcelona, Spain; ${ }^{2}$ Department of Meteorology and Air Quality, Wageningen University, 6701 AP Wageningen, The Netherlands

(Manuscript received 2 October 2000; in final form 18 October 2001)

\section{ABSTRACT}

Zenith Total Delay (ZTD) observations and model calculations are used to analyze a mesoscale convective system which yielded a large amount of precipitation over a short period of time in the north-western Mediterranean. ZTD observations are derived from the GPS signal delay whereas the ZTD model results are calculated by means of the MM5 mesoscale model.

Large values of the root-mean-square (rms) differences between the ZTD derived from the observations and the modeling are found for the maximum activity of the mesoscale convective system. It appears that the average bias between observations and modeling results is slightly affected $(20 \%)$ by the passage of the storm system which is associated to the water vapor variability of the atmosphere.

We have analyzed the ZTD differences in terms of the two components: the Zenith Hydrostatic Delay (ZHD) and the Zenith Wet Delay (ZWD). The hydrostatic error is mainly caused by the differences between the elevation of the GPS stations and the model topography and is reduced when using a more accurate topography data set. We propose a correction for this error assuming hydrostatic equilibrium. The remaining average ZTD difference is associated to the ZWD and is mainly generated by inaccuracies of the mesoscale model to predict the water vapor content during the rainfall event.

\section{Introduction}

The Global Positioning System (GPS) procedure is sensitive to the horizontal and temporal distribution of the precipitable water (PW) content in the atmosphere (e.g. Bevis et al., 1992; Rocken et al., 1995; Businger et al., 1996; Duan et al., 1996). The GPS-derived PW can be used to monitor numerical weather prediction (NWP) models (Yang et al., 1999; Cucurull et al., 2000). In both studies a low-resolution hydrostatic model was used and the focus was on GPS-derived PW analysis. It is therefore necessary to further investigate if these conclusions found in previous works

\footnotetext{
* Corresponding author. e-mail: cucurull@ieec.fcr.es
}

still apply when high-resolution models are used, i.e. non-hydrostatic models, and for situations where trigger mechanisms such as surface heating or orographic uplift can lead to sudden changes in the water vapor distribution.

The western Mediterranean is frequently affected by situations connected with heavy rainfalls over localized areas (less than $10 \mathrm{~km}$ ) and during a short time (less than $2 \mathrm{~h}$ ). These events are mostly the results of mesoscale convective systems (Llasat and Puigcerver, 1992; Ramis et al., 1994; Codina et al., 1996; Romero et al., 1998) which are closely related to the land surface heat flux conditions and the topography of the area.

The aim of this paper is to use precise and continuous measurements of the water vapor column by means of the GPS technique to study 
the evolution of a mesoscale convective system at the northeast coast of the Iberian Peninsula. This region has complex orography and the surface conditions are very heterogenous (from heavily urbanized areas to forest and bare soil). The GPS observations are compared to the ZTD values calculated by means of fine-scale modeling for the same situation by using the MM5 Modeling System (Anthes and Warner, 1978; Dudhia, 1993; Grell et al., 1994).

The case study was carried out on 14 September 1999 during the evolution of a mesoscale convective system which produced a large amount of precipitation in the area. In order to assess the dependence of the GPS data on the meteorological situation, an additional day with absence of precipitation and low moisture variability was selected (10 September 1999).

A continuous monitoring of the ZTD is carried out by five GPS receivers located at several sites in the NW Mediterranean region. The contributions to the ZTD fluctuations are analyzed in terms of the two components (Davis et al., 1985; Bevis et al., 1992): the ZHD and the ZWD, i.e. $\mathrm{ZTD}=\mathrm{ZHD}+\mathrm{ZWD}$. The ZHD is the largest term and can be accurately calculated if measurements of surface pressure are available (Saastamoinen, 1972). The ZWD is associated with the atmospheric water vapor and is very difficult to model because of its high variability (Emardson et al., 1999). From the ZWD, one can derive the PW variable $(1 \mathrm{~cm}$ of ZWD converts to around $6.6 \mathrm{~cm}$ of PW) (Bevis et al., 1992).

The structure of the present paper is as follows. Section 2 describes the meteorological situation under study. The location and treatment of the GPS observations and the non-hydrostatic model simulations are briefly described in Section 3. Section 4 presents the results of the sensitivity analyses of the comparison between the modeled and GPS-derived values. The main conclusions are drawn in the last section.

\section{Meteorological situation}

The meteorological situation under study was the result of the interaction of two atmospheric phenomena. On 14 September 1999 around noon a thermal low was well developed above the center of the Iberian Peninsula. The origin of the thermal low is a synoptic situation characterized by a low-pressure area over the North of Africa, Mediterranean sea, and eastern coast of the Iberian Peninsula which is reinforced by the intense heating of the land surface in the previous days. During the afternoon this system moved eastward due to the passage of a sharp and deep trough which crossed the Iberian Peninsula with a NW-SE jet stream behind the trough axis. This trough simultaneously intensified the cyclogenesis over the eastern Iberian Peninsula and the Mediterranean sea. At 18 UTC the low center was situated above the eastern coast (see Fig. 1). As a result, moist and warm air was advected from the Mediterranean into the NE of the Iberian Peninsula and the Gulf of Lion. The radiosonde measurements showed at 00 UTC on 15 September a nearly saturated atmosphere from above $850 \mathrm{hPa}$ up to $200 \mathrm{hPa}$. The synergism of the surface phenomena, low level advection of moist and warm air, and upper conditions, through transporting cold air and intensifying the cyclogenesis and convection over the area, was

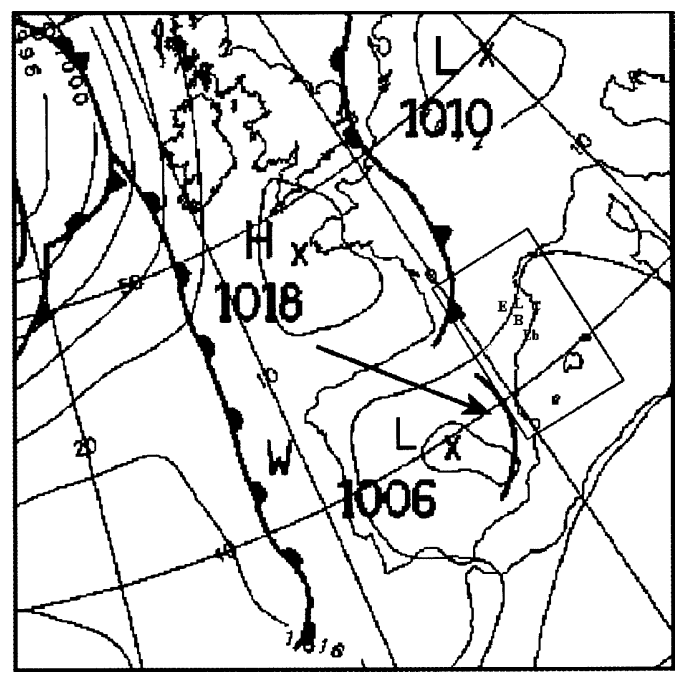

Fig. 1. Surface analysis of the atmospheric flow at 18 UTC 14 September 1999. The arrow indicates the movement of the trough. The geographical location of the GPS sites (E for ESCO, L for LLIV, C for CREU, $\mathrm{B}$ for BELL, Eb for EBRE) are indicated at the $6-\mathrm{km}$ grid resolution domain used in the MM5 model. The weather chart has been adapted from a map given by the UK Met-Office. 
the origin of the active mesoscale convective system over the NE Iberian Peninsula.

The rainfall precipitation measured was $80 \mathrm{~mm}$ in the East of Catalonia between 00 UTC 14 September and 00 UTC 15 September. At several stations this precipitation fell in a short time and with high intensity. (For instance the city of Barcelona received $55 \mathrm{~mm}$ in $40 \mathrm{~min}$ with $3 \mathrm{~cm}$ of hail).

To compare the GPS observations with the MM5 results under different meteorological conditions, we have selected a second meteorological event characterized by a cloudless sky, high temperature, and a high-pressure situation. The selected dry and relative low values of water vapor period corresponds to 10 September 1999.

\section{Methodology}

\subsection{GPS data}

The GPS network consists of five Trimble 400SSI GPS receivers operated by the Institut Cartogràfic de Catalunya (ICC). The names and heights above sea level of these stations are shown in Table 1. These GPS sites form baselines ranging in length from about 100 to $350 \mathrm{~km}$ with maximum altitude difference between GPS sites of about $2400 \mathrm{~m}$. The geographical location of the GPS sites covers from around $0^{\circ}$ to $4^{\circ} \mathrm{E}$ and from $40^{\circ} \mathrm{N}$ to $43^{\circ} \mathrm{N}$.

We use the GPS precise orbits and clocks as well as consistent earth-rotation parameters provided by the International GPS Service (IGS) together with the GIPSY/OASIS-II (version 4) software package (Webb and Zumberge, 1993) to estimate ZTD (taken every $15 \mathrm{~min}$ ) at the five GPS sites with a formal error of $0.5 \mathrm{~cm}$. This software uses a stochastic filter to provide timedependent estimates of the atmospheric delays for each site.

\subsection{Model setup}

The NCAR/Penn State MM5 Modeling System is used to simulate the ZTD variable. The MM5 is a primitive equation, finite-difference based nonhydrostatic mesoscale model (Dudhia, 1993).

We set up three (2-way nested) domains with grid distance ranging from $54 \mathrm{~km}$ down to $6 \mathrm{~km}$. At the finest domain the grid dimensions are 82 grid points in the north-south direction, 97 in the east-west direction, and 24 vertical sigma levels (see Fig. 1). A 5 arcmin topographic source is used for the third domain. To investigate the impact of modeling prescribing a finer grid resolution and a more accurate topography source, we have defined five additional nested domains, each one centered at the location of a GPS receiver. At these fine domains, a grid resolution of $2 \mathrm{~km}$ is prescribed with a mesh of $52 \times 52 \times 24$, and a 30 arcsec topography source. The physical options used are: the high-resolution Blackadar parameterization of the planetary boundary layer (PBL), multi-layer soil model, the simple scheme of Dudhia (1993) for explicit moisture parameterization, and the clouds are explicitly solved for the smaller domains (grid resolutions of $6 \mathrm{~km}$ and $2 \mathrm{~km}$ ).

The initial and boundary conditions are provided by the European Center for Medium Range Forecasts (ECMWF) analysis at 00 UTC 10 and 14 September 1999 in order to study the two different meteorological situations. Both simulations are integrated for a $24 \mathrm{~h}$ period. ZTD values are calculated (15-min interval) at all grid points by adding the simulated ZHD and ZWD compon-

Table 1. Altitude of the GPS stations and elevation from different topographic sources, together with the average bias and rms (in brackets) between GPS-derived ZTD and MM5 modeled values for all the stations

\begin{tabular}{lccccc}
\hline \multicolumn{1}{c}{ Source } & ESCO $(\mathrm{M})$ & LLIV $(\mathrm{M})$ & BELL $(\mathrm{M})$ & CREU $(\mathrm{C})$ & EBRE $(\mathrm{C})$ \\
\hline Station height $(\mathrm{m})$ & 2458 & 1418 & 803 & 83 & 58 \\
5 arcmin height $(\mathrm{m})$ & 2097 & 1553 & 652 & 0 & 71 \\
ZTD bias and rms $(\mathrm{cm})$ & $-7.1(0.7)$ & $5.5(1.4)$ & $-2.4(1.8)$ & $-2.8(1.3)$ & $1.0(2.2)$ \\
30 arcsin height $(\mathrm{m})$ & 2310 & 1273 & 726 & 0 & 14 \\
ZTD bias and rms $(\mathrm{cm})$ & $-1.4(0.7)$ & $-2.3(1.3)$ & $-0.1(1.7)$ & $-2.6(1.1)$ & $-0.4(2.1)$ \\
\hline
\end{tabular}

M: mountain site, $\mathrm{C}$ : coastal site. 
ents. A bilinear interpolation from the four closest grid point values is used in the horizontal in order to estimate the simulated ZTD at the GPS sites.

\section{Results of the sensitivity analyses}

\subsection{ZTD differences due to the meteorological situation}

The development and evolution of a mesoscale convective system is studied in terms of the ZTD differences at a maritime (EBRE) and a mountain (LLIV) station. First, we have used the model resolution of $6 \mathrm{~km}$ and a topography source of 5 arcmin to simulate the ZTD variable at these GPS sites. In the simulations, the same parameterization of physical processes is used.

Figure 2 shows the 3 -h interval rms fluctuations of ZTD and the PW modeled by means of MM5 for 14 September 1999. Hereafter, all the rms values are calculated around the mean value. The increase in the rms value at selected sites during the second half of day 14 (more than $1 \mathrm{~cm}$ of ZTD) reveals a high variability of the ZTD variable during this period which corresponds to the activity of the mesoscale convective system. The fluctuations of the ZTD are mainly the ZWD contribution due to the variations in the water vapor content. This can be also observed in the figure where the modeled PW variable has been represented at the same sites and for the same period. The rise and high variability of the PW starting at about 12 UTC 14 September correlates with the increase of the rms value and with the

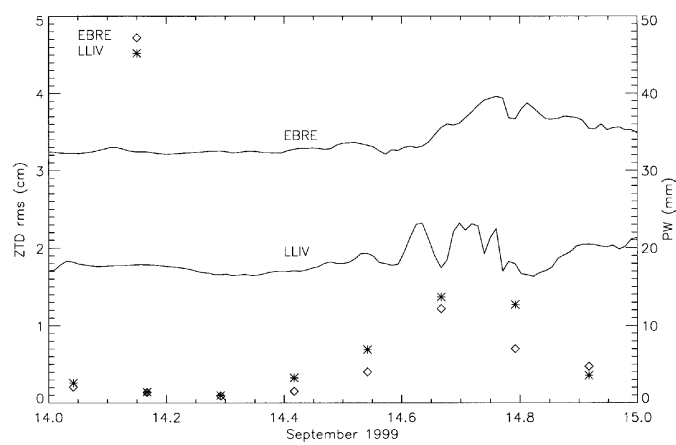

Fig. 2. 3-h interval rms ZTD errors ( * LLIV, $\diamond$ EBRE) and modeled precipitable water (continuous line) as a function of time at LLIV and EBRE stations. large precipitation recorded in the area. During 10 September (clear day), there is almost no variation in the ZTD fluctuation, and the average rms values for LLIV and EBRE sites are $0.3 \mathrm{~cm}$ of ZTD. A similar behaviour is found for the rest of the GPS stations.

We next turn our attention to compare the differences between the GPS-derived ZTD values and the ZTD simulations using MM5 with the grid resolution of $6 \mathrm{~km}$. The frequency distribution of these differences for 14 September are presented in Fig. 3a. The histogram for the mountain station LLIV (grey) shows its maximum frequency between 5 and $6 \mathrm{~cm}$ of ZTD difference with an average bias of $5.5 \mathrm{~cm}$ (observations values are higher than the MM5 results) and a rms value of $1.4 \mathrm{~cm}$. The EBRE coastal site error distribution (white) presents an average bias of $1.0 \mathrm{~cm}$ of ZTD (observations are higher than the model simulations) and a rms of $2.2 \mathrm{~cm}$ of ZTD. In that case, the data distribution is more centered at zero but the rms of the histogram is higher than for the mountain station.

In order to study the impact of the meteorological conditions on those frequency distributions, Fig. $3 \mathrm{~b}$ shows the same analyses of distribution but for 10 September 1999. Although there is still some positive bias between the observations and the modeled ZTD (average bias of $4.5 \mathrm{~cm}$ of ZTD at LLIV and $0.8 \mathrm{~cm}$ of ZTD at EBRE), the data distribution is more centered around its mean ( $\mathrm{rms}$ of $1.0 \mathrm{~cm}$ at LLIV and $1.6 \mathrm{~cm}$ at EBRE) which corresponds to a lower variability of the ZTD differences between the model and the observations. This is reasonable since we have found that in clear days the evolution of ZTD shows lower variability than in a stormy period. Similar results are found for the other stations treated in the study.

As Fig. 3 shows, the mountain station has a large bias in 14 September, while a lower bias is obtained for the coastal site. When the clear day is analyzed the average bias decreases by around $20 \%$ of its original value at both GPS stations. This reduction may be due to a decrease of the differences between the observed and modeled ZHD or it may be attributed to a more accurate modeling of the PW variable during the clear day. Measurements of surface pressure at GPS sites are needed to evaluate the former in order to compare the observed pressure data with the 

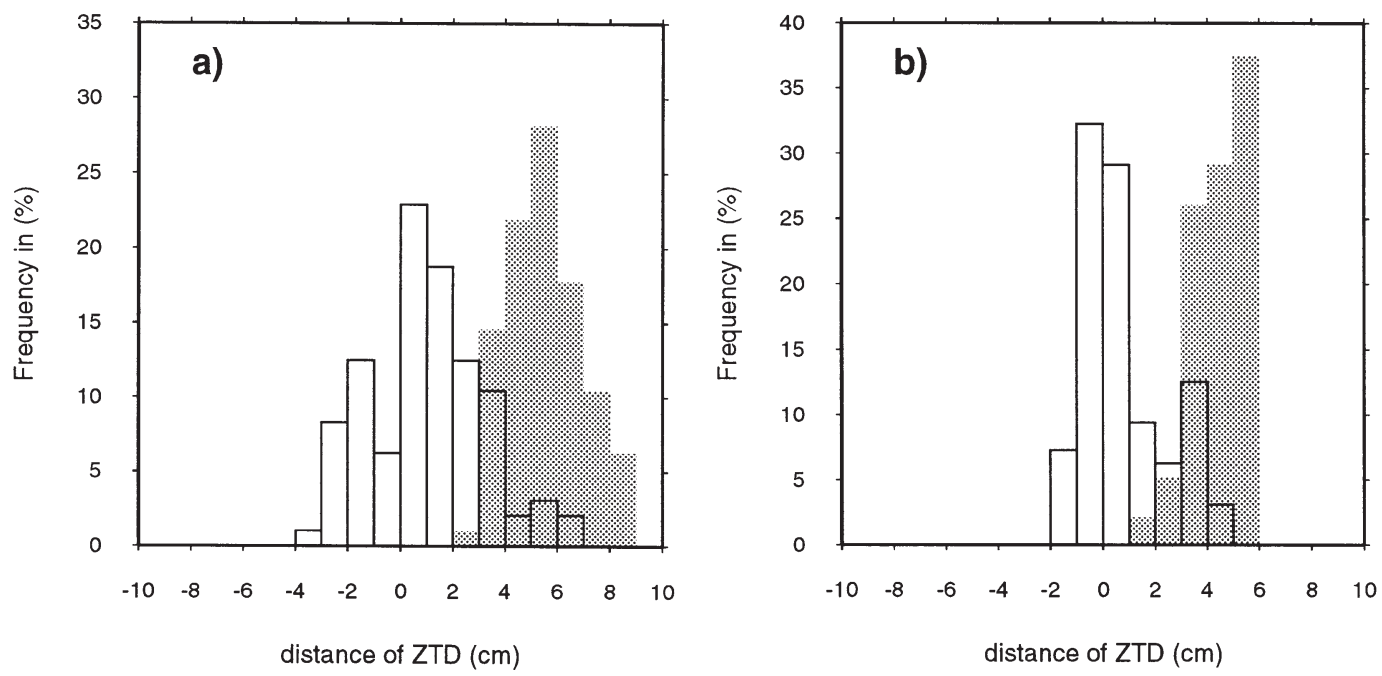

Fig. 3. Frequency distribution of the differences between the GPS-derived ZTD observations and the modeled values (low grid and topography resolutions) at LLIV (grey) and EBRE (white) stations during (a) 14 September 1999 and (b) 10 September 1999 .

values predicted by the meteorological model and thus evaluate the ZHD term. The only groundbased receiver from our GPS network that operates a barometer is CREU station. For this site, the average bias between the observed pressure and the values obtained with the model accounts for around $10 \mathrm{mb}$ or $2 \mathrm{~cm}$ of ZHD (higher model values) in both meteorological situations. This shows that the ZHD component is almost insensitive to the atmospheric conditions. Therefore, the decrease of the average ZTD bias is due to the water vapor contribution term (ZWD), while the hydrostatic component remains unchanged.

To verify this decrease, we have used the PW derived from the GPS measurements and the surface pressure observations taken at CREU station. The average difference between the GPSderived PW and the model simulation at this site shows a tendency towards lower values of PW in agreement with the average $\mathrm{PW}$ evolution during 10 September 1999.

Assuming now that all the average ZTD bias for EBRE and LLIV stations is also due to the moisture component, the reduction of the average ZTD bias on 10 September 1999 accounts for about $1.5 \mathrm{~mm}$ and $0.3 \mathrm{~mm}$ of PW at LLIV and EBRE stations, respectively.

The variability of the water vapor content slightly reduces the differences between the ZTD observations and the modeled values, but it is not the main source for such a bias. In the next section, we analyze this average bias by simulating the mesoscale convective system with a finer grid and topography database.

\subsection{ZTD differences due to the topography and model resolution}

We have selected two model configurations to analyze the impact of the topographic and modeling resolutions on the ZTD differences between observations and modeled values. We have used a topography source of 5 arcmin for the lower model resolution tested $(6 \mathrm{~km})$ and the fine data set of 30 arcsec for the higher grid resolution $(2 \mathrm{~km})$. The physical processes were parameterized in the same way for both cases.

The elevations from the different topographic sources are shown in Table 1. The mountain stations ESCO and BELL are better represented by the 30 arcsec resolution source when compared to the GPS heights, but we do not find the same situation for the coastal sites and LLIV. Both, the 5 arcmin and 30 arcsec landuse categories misrepresent CREU station, which is described as a water body. It should be mentioned that this station is situated on a cliff. The lower resolution topography results are more appropriate than the 
30 arcsec source to model the height of EBRE station. For LLIV, the difference between the station height and the elevation modeled using the 5-arcmin and 30-arcsec topography sources is the same. Therefore, we cannot expect an improvement on the ZTD simulation with the use of a finer terrain database.

Figure 4 shows the frequency distribution of the ZTD differences between observations and modeling simulations at ESCO station for 14 September. The grey histogram corresponds to the lower topographic resolution, whereas the white histogram depicts the ZTD differences calculated with the finest data set. The average bias of these ZTD fluctuations is largely reduced when the 30 arcsec topography source is used. Although the frequency of the distribution is similar in both histograms, the ZTD values simulated using the finest topographic data agree better with the observations than when the coarse data resolution is used. This means that the impact of the topography is to reduce (for the fine source) or to increase (for the low-resolution source) the average ZTD bias (mainly through the ZHD contribution). However, it does not affect the variability (rms) of these differences.

This result shows that the ZTD value strongly

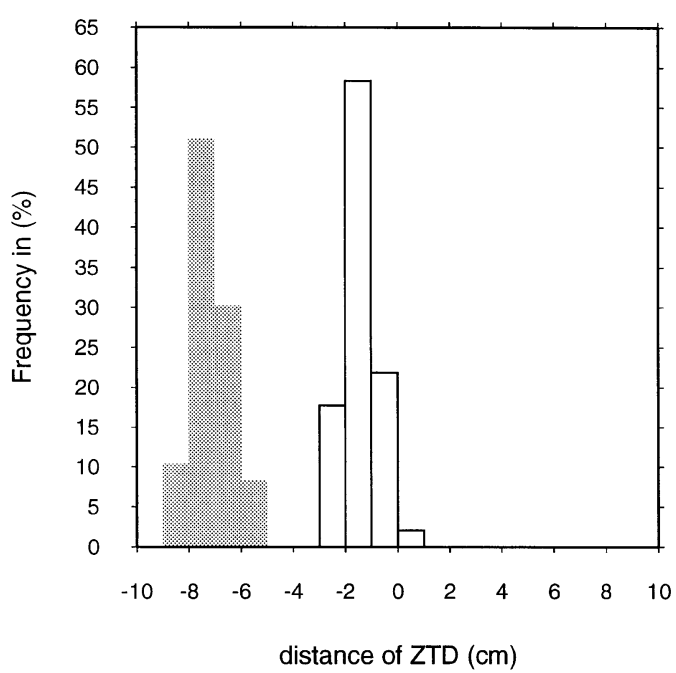

Fig. 4. Frequency distribution of the differences between the GPS-derived ZTD observations and the modeled values at ESCO station during 14 September 1999 using a 5 arcmin topographic and land-use sources (grey) and 30 arcsec topographic and land-use data sets (white). depends on the height of the GPS station, but its variability is mainly driven by the meteorological conditions as was seen in the previous section. We have found similar results for all the GPS sites analyzed in this study (Table 1). The table shows the average bias and rms values for the two topographic sources tested. The average bias decreases largely at mountain stations when the fine topography is used. The resolution of the selected source slightly affects the mean difference at CREU, which is consistent with the inaccurate height given by the topography data source. Although the lower topography resolution source simulates slightly better the orography of EBRE site, a smaller reduced bias is obtained with the fine data set. This is mainly caused by a more appropriate vegetation category from the 30 arcsec source and the use of a higher model grid resolution.

The ZTD variable depends on the atmosphere layer depth between the GPS satellite and the receiver. This value increases for denser atmospheres and longer trajectories of the signal. As a consequence, for a given atmospheric profile, the ZTD variable will be larger at the receivers located at the sea level in comparison to those situated on mountain tops. From the table, all the stations which have a model height below (above) the GPS sites present a larger (smaller) simulated ZTD than the observed values. For instance, ESCO has a real value of $2458 \mathrm{~m}$ compared to the $2310 \mathrm{~m}$ given by the $30 \mathrm{arcsec}$ data source. As a result of this difference, the ZTD bias is negative $(-7.1 \mathrm{~cm})$.

The increase of the ZTD differences between observations and modeled values with the use of the 5 arcmin topography resolution when compared to the finer data set may be explained in two ways: (a) it may be caused by a bias in the station pressure entering in the ZHD calculation due to the low terrain resolution or (b) it may be produced by innacurate predictions of the PW content. In order to analyze these two different contributions, the average difference between ZTD obtained with high- and low-resolution topography are shown in Table 2 for all the stations.

The table also includes the hydrostatic contribution to the ZTD bias due to innacurate modeling of the surface pressure variable due to the use of the low terrain data set. The highest differences in the ZHD variable between both topographic sources are found for the mountain stations, which

Tellus 54A (2002), 2 
Table 2. Average difference and rms (in brackets) between the model simulations of ZTD, ZHD and PW variables with the use of a 5 arcmin topography source and the values obtained with a 30 arcsec finer terrain database

\begin{tabular}{lrrr}
\hline \multicolumn{1}{c}{ Station } & $\begin{array}{c}\text { Modeled ZTD bias (rms) } \\
(\mathrm{cm})\end{array}$ & $\begin{array}{c}\text { Modeled ZHD bias (rms) } \\
(\mathrm{cm})\end{array}$ & $\begin{array}{c}\text { Modeled PW bias (rms) } \\
(\mathrm{mm})\end{array}$ \\
\hline ESCO (M) & $5.7(0.5)$ & $4.5(0.1)$ & $1.8(0.8)$ \\
LLIV (M) & $-7.8(1.0)$ & $-6.5(0.1)$ & $-2.1(1.6)$ \\
BELL (M) & $2.3(1.0)$ & $1.7(0.1)$ & $0.9(1.5)$ \\
CREU (C) & $0.2(0.6)$ & $0.0(0.1)$ & $0.3(0.9)$ \\
EBRE (C) & $-1.4(0.8)$ & $-1.5(0.1)$ & $0.1(1.3)$ \\
\hline
\end{tabular}

are the stations with higher differences between 5 arcmin and 30 arcsec derived elevations. Since the elevation of CREU is always inaccurately given by both data sets, no differences are found for the simulated ground pressure variable. As opposite to this coastal site, all the ZTD bias is attributed to the hydrostatic term at EBRE site.

The remaining average difference of ZTD when using different topography and model resolutions can be attributed to the moisture content of the atmosphere. The average difference between the PW simulations with the use of a low and fine terrain data sets is also shown in Table 2. Generally, the lower model resolution results in an overestimation of the PW variable compared to the finer simulation during 14 September. The opposite situation is only found at LLIV station, which also showed a negative biased ZTD difference. We also note that the average PW difference between using the lower and higher topography sources is larger at mountain stations and ranges between $1 \mathrm{~mm}$ and $2 \mathrm{~mm}$ of PW.

We next investigate the hydrostatic and moisture contributions to the average difference between the GPS-derived ZTD and the values simulated with MM5 (see Table 1).

\subsection{Correction to remove the ZHD bias}

In the previous section we have shown that large ZTD differences results from the use of different topographic resolutions. The major part of this bias comes from the inaccurate calculation of the hydrostatic component (ZHD). In the following, we propose a procedure to correct for this bias.

The modeling of the ZHD using the coarse and fine topography data sources is used to infer the hydrostatic component of the average ZTD difference between observations and model simulations. This component is estimated by analyzing the differences between the pressure values predicted for the locations of the GPS sites as a function of the height increment. The pressure calculation is mainly governed by the hydrostatic equation (non-hydrostatic effects are of second order) and it depends on the physical options selected in the model, on the latitude, and on the weather situation. The correction to remove the ZTD difference bias due to the ZHD contribution can be easily applied to other meteorological models.

Figure 5 compares the average ZTD difference

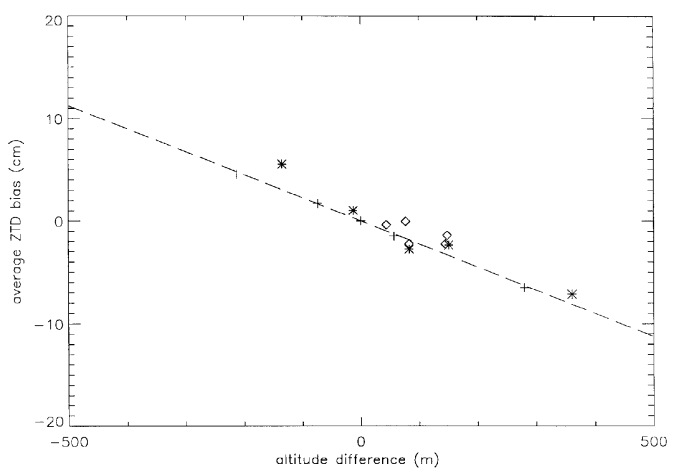

Fig. 5. Comparison of the ZTD differences between the GPS estimates and MM5 modeled values as a function of the altitude increment $(\Delta z)$ for 5 arcmin (asterisk), and 30 arcsec (diamond) topographic sources for 14 September 1999. The dashed line $(-0.0225 \Delta z-0.1348)$ fits the average ZHD differences between the model simulations with the 5 arcmin and 30 arcsec topography sources as a function of the altitude increment, and shows the ZTD variation assuming hydrostatic equilibrium in the atmosphere. 
between the observations and the simulated values against the difference between the stations and modeled heights for the topographic sources under study. A straight-line fit to these data yields a slope of $-0.024 \pm 0.003$ (for the 5 arcmin source, in asterisk), and $-0.013 \pm 0.010$ (for the 30 arcsec source, in diamond). The $\chi^{2}$ (per degree of freedom) are 1.3 and 0.7 , respectively. In the figure, the dashed line fits the average ZHD differences between the model simulations with the use of the 5 arcmin and 30 arcsec topography sources as a function of the altitude increment $\Delta z$ (in cross) which are summarized in Table 2. This line yields a slope of $-0.0225 \pm 0.0004$ and gives the ZTD variation as a function of the altitude increment assuming that the atmosphere is in hydrostatic equilibrium. For instance, ESCO has an elevation of $2458 \mathrm{~m}$ compared to the $2097 \mathrm{~m}$ given by the 5 -arcmin topography source. As a consequence, $\Delta z=361 \mathrm{~m}$ and the expected average ZHD difference between the observations and the model simulations is $361 \times(-0.0225)=-8.1 \mathrm{~cm}$.

The main difference between the ZTD derived from GPS and MM5 arises from the inaccurate values of the topography. The contribution to the average ZTD difference by assuming hydrostatic equilibrium is summarized in Table 3 for all the stations. The largest values of the derived ZHD differences are found at mountain stations for all the topographic sources tested in this study. As expected, no differences are found at CREU station between both terrain data sets. The value obtained at this coastal site $(-1.9 \mathrm{~cm}$ of ZHD) is consistent with the average ZHD derived from the differences between the modeled and observed surface pressure values (see Section 4.1). This good agreement confirms the validity of the slope of
-0.0225 used to infer the average ZHD difference from estimates of ZTD differences.

The remaining average bias of ZTD may be explained in terms of the high PW fluctuations due to development and evolution of the mesoscale convective system. This average bias on the moisture field ranges from -1.4 to $3.7 \mathrm{~mm}$ of $\mathrm{PW}$ for the low-resolution terrain database, and from -0.6 to $2.9 \mathrm{~mm}$ of $\mathrm{PW}$ for the fine topographic data set. In general, the simulations of PW underestimate the moisture content of the atmosphere when compared to the derived observations. The model only predicts a surplus of humidity field at CREU station. The largest PW differences are found at mountain stations, which also showed a higher average ZTD bias. A distinctive element of the table is that although the elevation of the GPS stations is in general better modeled with the use of the fine topography source, the simulation of the PW variable is not always improved by using a higher terrain resolution because it depends on the physical parameterization. The coastal and LLIV stations reduce their average PW bias when using the 30 arcsec topography source, while ESCO and BELL sites increase the average difference between observed and modeled PW with the fine database by around $1 \mathrm{~mm}$ of $\mathrm{PW}$.

\section{Conclusions}

The zenith total delay observed and modeled during the occurrence of a mesoscale convective system is studied. The emphasis is placed on the analysis of the hydrostatic and moisture contributions to the differences between the ZTD observed and calculated in a situation with high water

Table 3. Contribution of the surface pressure (related to ZHD) and moisture variable (related to PW) to the average ZTD difference between the GPS-derived observations and model simulations with the use of 5 arcmin and 30 arcsec topography sources

\begin{tabular}{lccccc}
\hline \multicolumn{1}{c}{ Source } & ESCO (M) & LLIV $(\mathrm{M})$ & BELL (M) & CREU (M) & EBRE (C) \\
\hline 5 arcmin & & & & -1.9 & 0.3 \\
ZHD bias (cm) & -8.1 & 3.0 & -3.4 & -1.4 & 1.1 \\
PW bias (mm) & 1.4 & 3.7 & 1.5 & -1.9 & -1.0 \\
30 arcsec & & & -1.7 & -0.6 & 0.9 \\
ZHD bias (cm) & -3.3 & -3.3 & 2.5 & & \\
PW bias (mm) & 2.9 & 1.5 & & & \\
\hline
\end{tabular}

Tellus 54A (2002), 2 
vapor variability. The impact of the topography and model resolutions is studied by doing simulations with different resolutions.

The area under study is the NW Mediterranean region which is characterized by complex orography and heterogenous land surface conditions. The case selected was 14 September 1999 due to the large precipitation recorded in the area and the high variability of the water vapor content. In order to compare the dependence of the ZTD results on the meteorological situation we also analyzed a clear day with high temperature and absence of precipitation.

Significant average bias between the observed and modeled ZTD values are found for the stormy meteorological situation at mountain stations using the lower model resolution tested in the analysis $(6 \mathrm{~km})$. Such biases are largely reduced when a fine 30 arcsec topography source and a higher grid resolution are used. However, the rms values are large for all topographic sources which indicates an increase of the variability of the ZTD differences between observations and modeled values during periods of high variability in the water vapor content. For the clear day, the average bias is only slightly reduced and this is found to be associated to the moisture content of the atmosphere. The rms errors largely decrease at all GPS stations.

Important differences are found in the average ZTD bias when different topography data sets are tested. Probability distributions of the ZTD differences show reasonable data distributions with large biases at mountain stations with the 5 arcmin topography source and the lowresolution model. These biases are mainly due to the large height differences between the GPS station elevation and the model topography. The use of a finer topographic data source and a higher grid resolution, results in a reduction of these ZTD differences. This reduction is due to a better simulation of the ZHD since the topography is better represented. We have proposed a correction for the topography-derived error contribution to the ZTD differences between observations and modeled simulations.

The remaining average bias is attributed to innacurate water vapor values given by the representations of the physical processes in the model. It is also found that the model tends to underestimate the moisture content of the atmosphere during the stormy situation analyzed in this study regardless of the topography source used.

\section{Acknowledgments}

We thank NCAR and Caltech/JPL for providing the MM5 model and GIPSY/OASIS-II package, respectively. We are also grateful to Javier Fernández (INM, Galicia, Spain) for valuable discussions on the meteorological situation. This work was partially supported by the EC grant MAGIC PL-972065.

\section{REFERENCES}

Anthes, R. A. and Warner, T. T. 1978. Development of hydrodynamic models suitable for air pollution and other mesometeorological studies. Mon. Wea. Rev. 106, 1045-1078.

Bevis, M., Businger, S., Herring, T. A., Rocken, C. Anthes, R. A. and Ware, R. H. 1992. GPS meteorology: remote sensing of atmospheric water vapor using the global positioning system. J. Geophys. Res. 97, $15,787-15,801$.

Businger, S., Chiswell, S. R., Bevis, M., Duan, J., Anthes, R. A., Rocken, C., Ware, R. H., Exner, T., Van Hove, T. and Solheim, F. S. 1996. The promise of GPS in atmospheric monitoring. Bull. Am. Meteorol. Soc. 77, 5-18.

Codina, B., Aran, M., Young, S. and Redaño, A. 1997. Prediction of a mesoscale convective system over Catalonia (Northeastern Spain) with a nested numerical model. Atmos. Phys. 62, 9-22.

Cucurull, L., Navascues, B., Ruffini, G., Elosegui, P.,
Rius, A. and Vilà, J. 2000. The use of GPS to validate NWP systems: the HIRLAM model. J. Atmos. Ocean. Tech. 17, 773-787.

Davis, J. L., Herring, T. A., Shapiro, I. I., Rogers, A. E. and Elgered, E. 1985. Geodesy by radio interferometry: effects of atmospheric modeling errors on estimates of baseline lengths. Radio Sci. 20, 1593-1607.

Duan, J., Bevis, M., Fang, P., Bock, Y., Chiswell, S. R., Businger, S., Rocken, C., Solheim, F. S., Van Hove, T., Ware, R. H., McClusky, S., Herring, T. A. and King, R. W. 1996. GPS meteorology: direct estimation of the absolute value of precipitable water. J. Appl. Meteorol. 35, 830-838.

Dudhia, J. 1993. A non-hydrostatic version of the Penn State/NCAR mesoscale model: validation tests and simulation of an Atlantic cyclone and cold front. Mon. Wea. Rev. 121, 1493-1513.

Emardson, T. R. and Derks, H. J. P. 1999. On the relation 
between the wet delay and the integrated precipitable water vapor in the European atmosphere. Meteor. Appl. 6, 1-12.

Grell, G. A., Duhia, J. and Stauffer, D. R. 1994. A description of the fifth-generation Penn State/NCAR mesoscale model (MM5). NCAR Tech. Note, NCAR/ TN-398+STR, National Center for Atmospheric Research, Boulder, CO, 138 pp.

Llasat, M. C. and Puigcerver, M. 1992. Pluies extremes in Catalogne: influence orographique et caracteriques synoptiques. Hydrologie Continentale 71/2, 99-115.

Ramis, C., Llasat, M. C., Genovés, A. and Jansa, A. 1994. The October-1987 floods in Catalonia: synoptic and mesoscale mechanism. Met. Apps. 1, 337-350.

Romero, R., Ramis, C., Alonso, S, Doswell III, C. A. and Stensrud, D. J. 1998. Mesoscale model simulation of three heavy precipitation events in the western Mediterranean region. Mon. Wea. Rev. 126, 1859-1881.
Rocken, C., Van Hove, T., Johnson, J., Solheim, F. S., Ware, R. H., Bevis, M. and Chiswell, S. R. 1995. GPS/ STORM - GPS sensing of atmospheric water vapor for meteorology. J. Atmos. Ocean. Tech. 12, 468-478. Saastamoinen, J. 1972. Atmospheric correction for the troposphere and stratosphere in radio ranging of satellites. The use of artificial satellites for Geodesy, Geophys. Monogr. Se., 15, (eds. S. W. Henriksen, A. Mancini and B. H. Chovitz), 247-251. AGU, Washington, D.C.

Webb, F. H. and Zumberge, J. F. 1993. An introduction to the GIPSY-OASIS-II. JPL Publ. D-11088.

Yang, X., Sass, B. H., Elgered, G., Johansson, J. M. and Emardson, T. R. 1999. A comparison of the integrated water vapor estimation by a NWP simulation and GPS observations. J. Appl. Meteorol. 38, 941-956. 